\title{
Fe speciation at the permafrost-active layer boundary
}

\author{
AMANDA BARKER ${ }^{1}$, GRACE MCINTURFF ${ }^{2}$, THOMAS \\ DOUGLAS $^{1}$, SHAWN GALLAHER ${ }^{3}$ AND JOSEPH SMITH ${ }^{3}$ \\ ${ }^{1}$ Cold Regions Research and Engineering Laboratory \\ ${ }^{2}$ U.S. Coast Guard Academy \\ ${ }^{3}$ U.S. Naval Academy \\ Presenting Author: Amanda.J.Barker@usace.army.mil
}

In arctic and sub-arctic regimes where permafrost accounts for a large portion of the soil environment, the unique interactions between the active layer (seasonally-thawed upper portion of soil) and permafrost (permanently frozen lower portion of soil) contribute an additional barrier to predicting surface water material flux. Permafrost contains a unique environmental interface at the active layer-permafrost transition zone characterized by a sharp redox gradient and a phase change from liquid water to frozen ice. The chemical composition and environmental conditions at this interface likely influence reactivity. As solid-phase water in permafrost thaws, a higher proportion of interfacial water may be present, disrupting the localized microenvironment of this transition zone. Associated changes could affect redox environment, speciation, water density, viscosity, conductivity, and soil wettability, which may accelerate degradation in nearby areas. Previous work shows the interface represents a reducing zone that is highly susceptible to mass flushing of redox active elements (e.g. iron; Fe) if thawed and this mass flush will likely occur in late fall/early winter when the active layer is at its' deepest yearly extent. As such, the delicate balance between the active layer and underlying permafrost acts as a significant control on watershed hydrobiogeochemistry. Our work shows bands of reduced Fe sit perched at the active layer permafrost boundary that partition to soil solution greater than the oxidized bands present at the surface of the soil column. Additionally, we observed high concentrations of $\mathrm{Fe}$ in the nearby surface water in late fall/early winter corresponding to when the soil surface is frozen, but the active layer is at its' deepest annual depth. As seasonal transitions become more intense in the arctic (winter to spring and fall to winter) and permafrost degradation accelerates, there will be rapid changes to the first 1-2 meters of the soil with potentially significant changes occurring at the permafrost-active layer interface. The majority of transport and soil stability prediction models do not incorporate this complex redox interface and modeling the extent permafrost degradation impacts watershed geochemistry is challenging, thus warranting further research. 